\title{
Inhibition of the MEK/ERK pathway reduces microglial activation and interleukin-1-beta expression in spinal cord ischemia/reperfusion injury in rats
}

Kang Lu, MD, PhD, ${ }^{\text {a }}$ Chung-Lung Cho, PhD, ${ }^{b}$ Cheng-Loong Liang, MD, ${ }^{a}$ Shang-Der Chen, MD, ${ }^{c}$ Po-Chou Liliang, MD, ${ }^{a}$ Shin-Yuan Wang, MS, ${ }^{d}$ and Han-Jung Chen, MD, PhD ${ }^{a}$

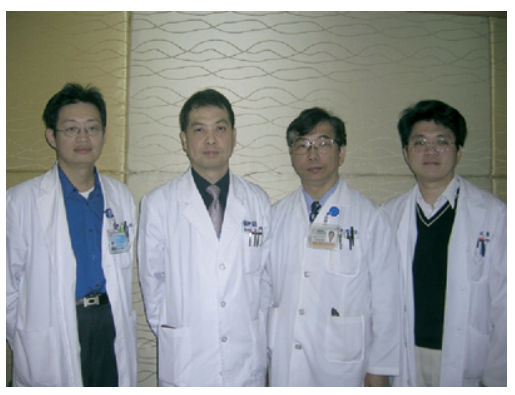

Drs Liliang, Lu, Chen, and Liang (left to right).

From the Departments of Neurosurgery and Medical Research, ${ }^{\mathrm{d}}$ E-Da Hospital, I-Shou University; Department of Biological Sciences, National Sun-Yat Sen University ; and Department of Neurology, Chang-Gung Memorial Hospital, ${ }^{\mathrm{c}}$ Kaohsiung, Taiwan.

Supported by research grants from the National Science Council, Taiwan (NSC932314-B-214-009 and NSC94-2314-B-214 013).

Received for publication Aug 18, 2006; revisions received Oct 12, 2006; accepted for publication Nov 3, 2006.

Address for reprints: Han-Jung Chen, MD, $\mathrm{PhD}$, Department of Neurosurgery, E-Da Hospital, I-Shou University, 1 E-Da Road, Yan-Chau Shiang, Kaohsiung 824, Taiwan (E-mail: chenmd@ms8.hinet.net).

J Thorac Cardiovasc Surg 2007;133:934-41

$0022-5223 / \$ 32.00$

Copyright $\odot 2007$ by The American Association for Thoracic Surgery

doi:10.1016/j.jtcvs.2006.11.038
Objectives: Ischemic spinal cord injury is a serious complication of aortic surgery. Although the extracellular signal-regulated kinases 1 and 2 are generally regarded as related to cell proliferation and survival, increasing evidence suggests that the role of the extracellular signal-regulated kinase pathway in ischemia/reperfusion injury is much more sophisticated.

Methods: Spinal cord ischemia in rats was induced by occluding the thoracic descending aorta with a balloon catheter introduced through a femoral artery, accompanied by concomitant exsanguination. Rats in the control group were given dimethyl sulfoxide (vehicle) before undergoing spinal cord ischemia/reperfusion injury. In the U0126-treated group, rats were pretreated with a specific inhibitor of the mitogenactivated protein kinase/extracellular signal-regulated kinases 1 and 2, U0126, to inhibit extracellular signal-regulated kinases 1 and 2 phosphorylation. The shamoperated rats underwent aortic catheterization without occlusion. Parameters, including neurologic performance, neuronal survival, inflammatory cell infiltration, and interleukin- $1 \beta$ production in the spinal cords, were compared between groups.

Results: Early extracellular signal-regulated kinases 1 and 2 phosphorylation was observed after injury in the control group, followed by abundant microglial accumulation in the infarct area and increased interleukin- $1 \beta$ expression. In the U0126 group, U0126 treatment completely blocked extracellular signal-regulated kinases 1 and 2 phosphorylation. Microglial activation and spinal cord interleukin- $1 \beta$ levels were significantly reduced. Neuronal survival and functional performance were improved.

Conclusions: The mitogen-activated protein kinase/extracellular signal-regulated kinase pathway may play a noxious role in spinal cord ischemia/reperfusion injury by participating in inflammatory reactions and cytokine production. Targeting this pathway may be of potential value in terms of therapeutic intervention.

$\mathrm{M}$ itogen-activated protein kinase (MAPK) pathways are crucial signal transducing cascades that transmit and integrate extracellular signals to mount an appropriate response. ${ }^{1}$ Among the subgroups of the MAPKs, the extracellular signal-regulated kinases 1 and 2 (ERK1/2), being phosphorylated by MAPK/ERK 1 and 2 (MAPK/ERK kinase [MEK]1/2) in response to growth factors, ${ }^{2,3}$ are generally regarded as being related to cell survival, proliferation, and differentiation. ${ }^{4,5}$ However, emerging evidence suggests that activation of ERK1/2 may lead to neuronal cell death. ${ }^{6-8}$ Inhibiting the MEK/ERK pathway was found to provide neuroprotection against oxidative stress, ${ }^{9}$ mechanical trauma, ${ }^{10}$ and seizurelike activity. ${ }^{11}$ In vivo studies showed that MEK/ERK inhibition decreased infarct volume and improved neuronal survival in animal models of cerebral ischemia, ${ }^{12,13}$ as well as deep hypothermic circulatory arrest. ${ }^{14}$ Despite these findings, the role of 


$$
\begin{aligned}
& \text { Abbreviations and Acronyms } \\
& \mathrm{CBP}=\text { carotid blood pressure } \\
& \text { CNS = central nervous system } \\
& \text { ERK = extracellular signal-regulated kinase } \\
& \text { GFAP = glial fibrillary acidic protein } \\
& \text { IL = interleukin } \\
& \mathrm{I} / \mathrm{R}=\text { ischemia/reperfusion } \\
& \text { MAPK }=\text { mitogen-activated protein kinase } \\
& \text { MEK }=\text { MAPK/ERK kinase } \\
& \text { MPO = myeloperoxidase } \\
& \text { p-ERK }=\text { phosphorylated extracellular signal-regulated } \\
& \text { kinase }
\end{aligned}
$$

the $\mathrm{MEK} / \mathrm{ERK}$ pathway in ischemia/reperfusion (I/R) injury of the central nervous system (CNS) has not been well explored.

Inflammation is a key pathologic feature of the CNS against a variety of insults. Proinflammatory cytokines secreted by activated microglia and recruited astrocytes may contribute to neuronal degeneration and cell death. ${ }^{15-17}$ Interleukin (IL)-1 $\beta$, in particular, has been shown to play a pivotal role in the development of acute neurodegeneration caused by ischemic, excitotoxic, and traumatic brain injury. ${ }^{18-20}$ Antagonizing IL-1 action reduced inflammation and neuronal loss in cerebral ischemia. ${ }^{21}$ Likewise, IL-1 receptor null mice showed significantly milder brain edema and tissue damage after ischemic brain injury. ${ }^{22}$

It was recently demonstrated that MEK/ERK inhibition significantly reduced infarct volume and proinflammatory cytokine expression after cerebral ischemia, implicating that the MEK/ERK pathway may be an important regulator of inflammatory responses in the brain. ${ }^{23}$ In the present study, we sought to clarify the role of the MEK/ERK pathway in spinal cord I/R injury, a devastating complication after aortic surgery. We hypothesized that this pathway is involved in mediating inflammation and cytokine expression after spinal cord I/R injury. We also examined whether inhibiting this pathway with the selective inhibitor U0126 could mitigate the severity of injury and provide neuroprotection.

\section{Materials and Methods Experimental Animals}

Adult male Sprague-Dawley rats weighing 350 to $400 \mathrm{~g}$ were used. Animals were housed 2 per cage, maintained on a 12-hour light-dark schedule at $22^{\circ} \mathrm{C}$, and allowed free access to food and water. Animal care and procedures were conducted in compliance with the guidelines for animal experiments of the National Science Council of this country.

\section{Animal Model of Spinal Cord Ischemia/Reperfusion Injury}

Anesthesia was induced with $2 \%$ to $3 \%$ isoflurane in oxygen and maintained with $1 \%$ to $2 \%$ isoflurane delivered through a face mask.
Rectal temperature was monitored with a probe (RET-2, Physitemp Instruments, Inc, Clifton, $\mathrm{NJ}$ ) and maintained at $37^{\circ} \mathrm{C} \pm 0.5^{\circ} \mathrm{C}$ with the Deltaphase Isothermal Pad (Braintree Scientific, Inc, Braintree, Mass). Spinal cord ischemia was induced by intraluminal balloon occlusion of the descending thoracic aorta as previously described. ${ }^{24}$ We applied concomitant hypovolemic hypotension during aortic occlusion, which we had found an effective modification to ensure spinal cord I/R injury of the same severity. ${ }^{25}$ The carotid blood pressure (CBP) was continuously monitored through a cannula in the left common carotid artery (PowerLab ADInstruments, ADInstruments Pty Ltd, Castle Hill, Australia). A 2F Fogarty arterial embolectomy catheter (Baxter Healthcare Corporation, Irvine, Calif) was advanced 10 to $11 \mathrm{~cm}$ into the descending thoracic aorta through an incision on the left femoral artery. The right femoral artery was cannulated with a 24-gauge intravenous cannula. Blood was withdrawn into a heparinized syringe until the mean CBP decreased to $50 \mathrm{~mm} \mathrm{Hg}$. The catheter balloon was inflated to completely occlude the descending thoracic aorta for 5 minutes. The catheter balloon was then deflated, and the withdrawn blood was slowly pushed into the right femoral artery to restore normal blood volume.

\section{Experimental Protocol}

Rats were randomly divided into 3 experimental groups. In the control group $(\mathrm{n}=12), 0.1 \mathrm{~mL}$ of $0.4 \%$ dimethyl sulfoxide in $0.1 \mathrm{M}$ phosphate-buffered saline was injected into the left femoral vein 20 minutes before spinal cord I/R injury. In the U0126-treated group (U0126 group, $\mathrm{n}=12)$, U0126 $(100 \mu \mathrm{g} / \mathrm{kg}$ in $0.1 \mathrm{~mL}$ of $0.4 \%$ dimethyl sulfoxide, Promega Corporation, Madison, Wis), a specific inhibitor of MEK1/2, was injected intravenously instead. In the sham-operated rats $(\mathrm{n}=3)$, exsanguination was induced in the same way. The Fogarty catheter was inserted into the thoracic aorta and left there for 5 minutes without inflation of the balloon, followed by restoration of blood volume. Rats were sacrificed under deep anesthesia at designated time points after injury. The segment of lumbar enlargement was cut transversely into 2 pieces. One was put into liquid nitrogen and stored at $-80^{\circ} \mathrm{C}$, and the other was fixed with formalin and embedded in paraffin. Only the lumbar segment was used for evaluation because of its vulnerability to ischemic injury. ${ }^{26}$

\section{Assessment of Neurologic Dysfunction}

Hind limb motor function was evaluated 3 hours after I/R injury and then daily until 7 days, based on a modified grading scale. ${ }^{24}$ The grades were as follows: 0, no neurologic deficit (normal); 1, mild weakness and/or gait disturbance, walking with toes flat under body; 2, knuckle-walking; 3, observable movements in the hind limbs, but unable to knuckle-walk; and 4, complete paralysis with or without spasticity. Rats not showing grade 3 or grade 4 dysfunction of at least 1 hind limb 3 hours after I/R injury were excluded. In rats with apparent asymmetry of motor function between the 2 hind limbs, the worse score was recorded.

\section{Immunohistochemistry}

Six-micrometer sections were deparaffinized and rehydrated. Antigen retrieval was done in boiled citrate buffer. A biotinylated secondary antibody (Immunotech, Marseille, France) was used. The antigen-antibody complexes were visualized using a streptavidin- 
horseradish peroxidase reagent (Immunotech) with amino-ethyl carbazol chromogen substrate (Immunotech). Sections were counterstained with hematoxylin.

The expression of phosphorylated ERK1/2 (p-ERK1/2) was examined with a p-ERK1/2 antibody (1:100, Cell Signaling Technology, Beverly, Mass). Neuronal survival was evaluated using a NeuN antibody (1:400, Chemicon International Inc, Temecula, Calif). The total number of neurons showing cytoplasmic NeuN staining in the gray matter on a section was counted. To investigate the nature of the cells infiltrating into the infarct area after I/R injury, sections were incubated with either 1 of 4 antibodies, including myeloperoxidase (MPO) antibody (1:100, Abcam, Cambridge, UK), a marker for polymorphonuclear neutrophils; ${ }^{27} \mathrm{CD} 14$ antibody (1:100, Santa Cruz Biotechnology, Santa Cruz, Calif), a marker for macrophages; ${ }^{28}$ OX42 (1:50, Serotec, Oxford, UK), a marker for microglia; ${ }^{29}$ and glial fibrillary acidic protein (GFAP) antibody (1:100, NeoMarkers, Fremont, Calif). The incubation condition was $4^{\circ} \mathrm{C}$ overnight for MPO, CD14, and OX42 antibodies, and room temperature for 1 hour for GFAP antibody.

\section{Determination of Interleukin-1 $\beta$ Content in Spinal Cords}

The lumbar segment of spinal cord was homogenized on ice in 300 $\mu \mathrm{L}$ of phosphate-buffered saline ( $\mathrm{pH} 7.4)$ with a mixture of protease inhibitors (Pierce, Rockford, Ill). Homogenates were subjected to centrifugation at $13,000 \mathrm{rpm}$ at $4^{\circ} \mathrm{C}$ for 20 minutes. Protein concentration was determined with the BCA Protein Assay Kit (Pierce, Rockford, Ill). The IL- $1 \beta$ content in spinal cord samples was quantified with a human IL-1 $\beta$ ELISA kit (Bender MedSystems, Vienna, Austria) according to the manufacturer's protocol. The change in absorbance on each well at $450 \mathrm{~nm}$ was measured by a spectrophotometer (TEAN DU-800 UV/Vis Spectrophotometer, Mannedorf, Switzerland). The IL- $1 \beta$ level was expressed as nanograms per microgram of total protein.

\section{Statistical Analysis}

Data are presented as mean \pm standard deviation. Comparisons of hind limb motor function, numbers of NeuN-positive cells, and IL-1 $\beta$ levels between the control and the U0126 groups were performed using a nonparametric method followed by the MannWhitney $U$ test. Statistical analyses were conducted with the Statistical Package for the Social Sciences 10.0 software (SPSS Inc, Chicago, Ill).

\section{Results}

In all rats, the rectal temperature was maintained at $37^{\circ} \mathrm{C} \pm$ $0.5^{\circ} \mathrm{C}$ during surgery. The mean body weight of shamoperated rats was $371.8 \pm 9.7 \mathrm{~g}(362-385 \mathrm{~g}, \mathrm{n}=3)$. The mean body weights of the control group and U0126 group were $375.9 \pm 7.1 \mathrm{~g}(367-388 \mathrm{~g}, \mathrm{n}=12)$ and $369.0 \pm 11.3 \mathrm{~g}$ (354-389 g, $\mathrm{n}=12$ ), respectively. The mean volume of blood withdrawn to reduce the $\mathrm{CBP}$ to $50 \mathrm{~mm} \mathrm{Hg}$ was $5.8 \pm 1.1$ $\mathrm{mL}(4.8-7.2 \mathrm{~mL})$ in the sham group, $6.0 \pm 0.8 \mathrm{~mL}(4.3-7.1$ $\mathrm{mL})$ in the control group, and $5.7 \pm 0.5 \mathrm{~mL}(4.8-6.8 \mathrm{~mL})$ in the U0126 group. No significant differences in these physiologic parameters existed between the groups.

\section{ERK1/2 Phosphorylation}

Low-level constitutive expression of p-ERK1/2 was observed in the sham-operated spinal cord samples. In the control group, I/R injury resulted in a strong induction of ERK1/2 phosphorylation in the spinal cord at 3 hours after injury. U0126 pretreatment completely abolished ERK1/2 phosphorylation, as reflected by the absence of $\mathrm{p}$-ERK1/2 expression. No significant difference of total ERK1/2 expression, used as an internal control, was observed between different samples (Figure 1, A). Immunohistochemistry showed faint $\mathrm{p}$-ERK1/2 expression on sham-operated spinal cord sections. Strong p-ERK1/2 immunostaining was observed in neurons and glial cells on control sections. However, on U0126 sections, p-ERK1/2 immunoreactivity was markedly suppressed (Figure 1,B).

\section{Neurologic Performance}

Sham-operated rats were neurologically intact after surgery. All rats of the control and U0126 groups demonstrated severe motor weakness of hind limbs at 3 hours after injury. U0126-treated rats tended to show more obvious functional recovery thereafter. Although improvement of hind limb motor function was also observed in the control group, the trend was less apparent. On the contrary, functional deterioration was not uncommon in the control group. Except for 3 hours $(P=.752)$ and 1 day $(P=.265)$ after injury, the U0126 group showed a significantly favorable functional grading than the control group at all time points of observation $(P=.032$ at 2 days, $P=.032$ at 3 days, $P=.025$ at 4 days, $P=.027$ at 5 days, $P=.037$ at 6 days, and $P=$ .019 at 7 days) (Figure 2).

\section{Neuronal Survival}

NeuN immunohistochemistry of spinal cord sections showed great distinction between the control and the U0126 groups. In the control group, exuberant infiltration of hematoxylinstained cells associated with dramatic loss of neurons was observed 3 days after injury (Figure 3, A). This was followed by extensive tissue destruction and cavity formation at 7 days (Figure 3, B). In contrast, the intensity of cellular infiltration and the severity of tissue damage and neuronal loss were all much milder in the U0126 group (Figure 3, C and $D$ ), giving rise to the histopathologic feature observed on a sham-operated section (Figure 3,E). The mean numbers of Neu-N-positive neurons per section were $367.8 \pm$ $26.9(\mathrm{n}=3)$ in the sham-operated rats; $139.6 \pm 20.6(\mathrm{n}=$ 4) at 3 days and $126.5 \pm 33.0(n=4)$ at 7 days in the control group; and $293.3 \pm 42.4(\mathrm{n}=4)$ at 3 days and $284.0 \pm 39.9$ $(\mathrm{n}=4)$ at 7 days in the U0126 group. The mean numbers of surviving neurons in the U0126 group were significantly higher than in the control group at 3 days $(P=.021)$ and 7 days $(P=.021)$ (Figure $3, F)$. 
A

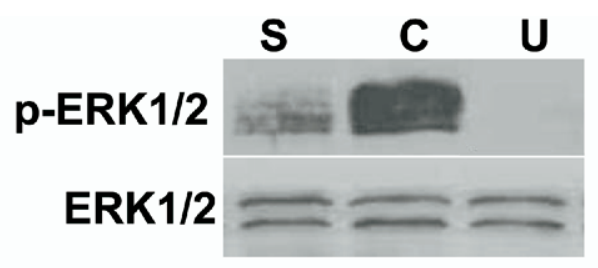

B
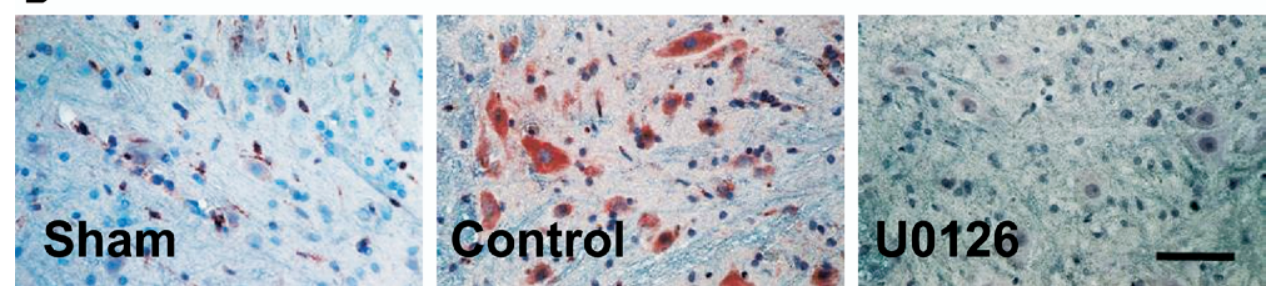

Figure 1. Effects of $I / R$ injury and U0126 on ERK1/2 phosphorylation. A, Western blot showing the expression of p-ERK1/2 in spinal cord samples obtained at 3 hours after injury, ERK1/2 being used as an internal control. Low constitutive expression of $p$-ERK1/2 was observed in the sham-operated sample (S). I/R injury induced an abrupt increase of $p$-ERK1/2 expression (C). Pretreatment with U0126 completely blocked ERK1/2 phosphorylation (U). B, Immunohistochemistry of $p$-ERK1/2 on spinal cord sections. Faint immunostaining was observed on shamoperated sections. Strong neuronal p-ERK1/2 expression was induced by I/R injury, which was abolished by U0126 treatment. Scale bar: $50 \mu \mathrm{m}$. ERK, Extracellular signal-regulated kinase.

Microglial and Astroglial Reactions

On the basis of the distinction of cellular infiltration between the control and the U0126 groups, we further investigated the nature of the infiltrating cells. Immunohistochemistry using different antibodies showed that these infiltrating cells were not immunostained by the MPO or

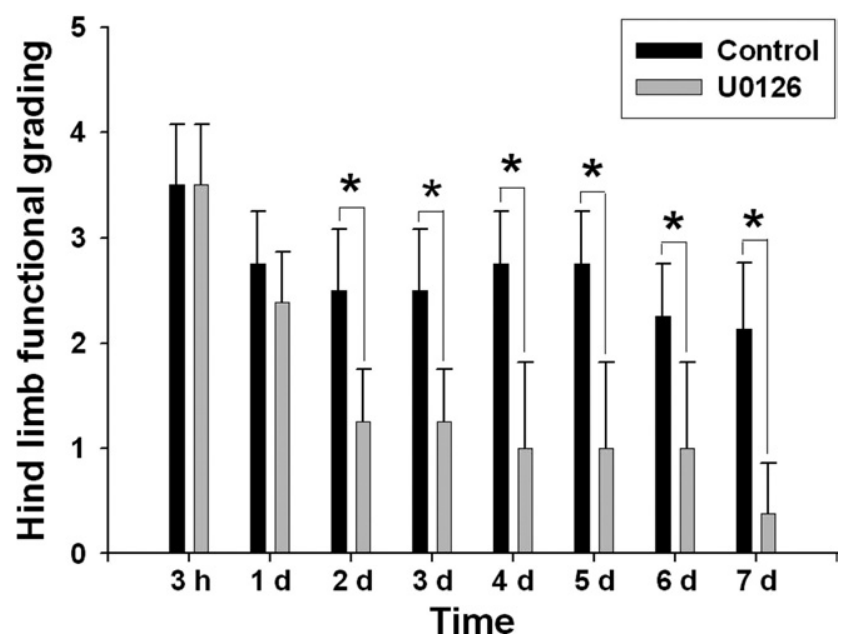

Figure 2. All rats showed severe hind limb motor dysfunction 3 hours after injury. U0126 group showed functional recovery significantly better than the control group ${ }^{*} P<.05, \mathrm{n}=4$ per time point in both groups).
CD14 antibodies, but only by the OX42 antibody. The infarct area was surrounded by cells demonstrating dense GFAP immunostaining and morphologic features of reactive astrocytes (Figure 4).

\section{Spinal Cord Interleukin-1 $\beta$ Content}

The calculated mean IL- $1 \beta$ amount (nanograms/microgram of total protein) in the sham-operated cord samples was $8.02 \pm 1.50(\mathrm{n}=4)$. The mean spinal cord IL- $1 \beta$ amounts in the control group were $20.38 \pm 2.49(\mathrm{n}=4)$ at 1 day and $19.69 \pm 3.21(\mathrm{n}=4)$ at 3 days. The mean spinal cord IL- $1 \beta$ amounts in the U0126 group were $9.73 \pm 2.49(\mathrm{n}=4)$ at 1 day and $8.67 \pm 2.27(n=4)$ at 3 days. The IL-1 $\beta$ levels in the control group were significantly higher than the sham value ( $P=.021$ for both time points). The IL- $1 \beta$ levels in the U0126 group were significantly lower than those in the control group ( $P=.021$ for both time points). No significant difference existed between the U0126 and the shamoperated samples $(P=.149$ for 1 day, and $P=.564$ for 3 days) (Figure 5).

\section{Discussion}

The major findings in this study regarding the effect of the specific MEK1/2 inhibitor U0126 on spinal cord I/R injury are as follows. U0126 showed a potent inhibitory effect on ERK1/2 phosphorylation in spinal cords after I/R injury. Previous studies demonstrated that this inhibitory effect of U0126 on ERK1/2 phosphorylation is dose dependent. ${ }^{9,13,23}$ 

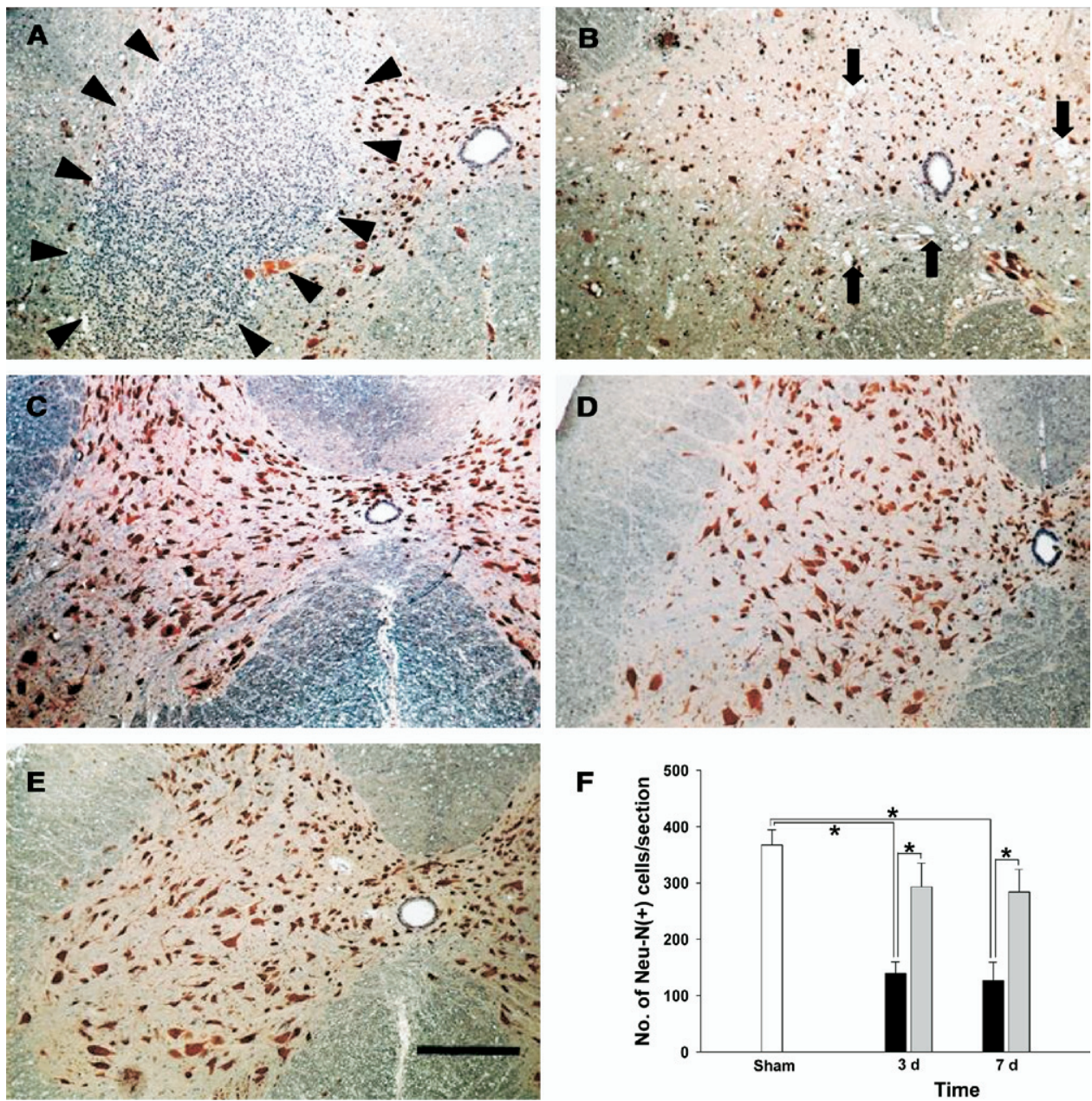

Figure 3. Neu-N immunohistochemistry of spinal cord sections obtained from the control (A, B) and U0126 (C, D) groups at 3 days $(A, C)$ and 7 days $(B, D)$ after injury. Exuberant cellular infiltration in the infarct area (arrowheads in A), tissue destruction, and cavitation (arrows in B) led to severe neuronal loss in the control group. U0126 treatment dramatically alleviated the injury severity, resulting in more surviving neurons showing NeuN immunostaining (C, D), a histopathologic feature on the sham-operated section (E). Scale bar, $200 \mu \mathrm{m}$. F, The mean numbers of NeuN-positive cells per section were significantly higher in the U0126 group than in the control group $\left.{ }^{*} \boldsymbol{P}=.021\right)$. Compared with the sham, the mean numbers in the control group were significantly lower $(\boldsymbol{P}=.021$ for 3 days and 7 days), whereas those in the U0126 group were not significantly different $(P=.149$ for 3 days, $P=$ .564 for 7 days).

Although Namura and colleagues ${ }^{13}$ showed maximal reduction of infarction volume after cerebral ischemia in mice with a U0126 dose of $200 \mu \mathrm{g} / \mathrm{kg}$, it was clear from their report that half-dose $(100 \mu \mathrm{g} / \mathrm{kg})$ pretreatment achieved almost the same protective effect. On the basis of these findings, in the present study, we chose to use the minimally required $100 \mu \mathrm{g} / \mathrm{kg}$ dose as our treatment regimen. Our data have proved this dose regimen effective both in inhibiting ERK1/2 phosphorylation and in reducing ischemic damage of the spinal cord in rats. Another interesting issue regarding U0126 administration is the timing. Wang and colleagues ${ }^{23}$ demonstrated that U0126 injected 20 minutes after middle cerebral artery occlusion had no effect in reducing ERK1/2 phosphorylation. Namura and colleagues ${ }^{13}$ also showed that the efficacy of U0126 in reducing brain infarct volume after cerebral ischemia declined with time in posttreatment compared with pretreatment. In a preliminary experiment, we found that U0126 given intravenously 1 hour after spinal cord I/R injury (100 $\mu \mathrm{g} / \mathrm{kg}$ ) failed to inhibit ERK1/2 phosphorylation. These findings suggest that ERK1/2 phosphorylation is an early event triggered by the ischemic insult. Therefore, pretreatment before ischemia is a rational ap- 

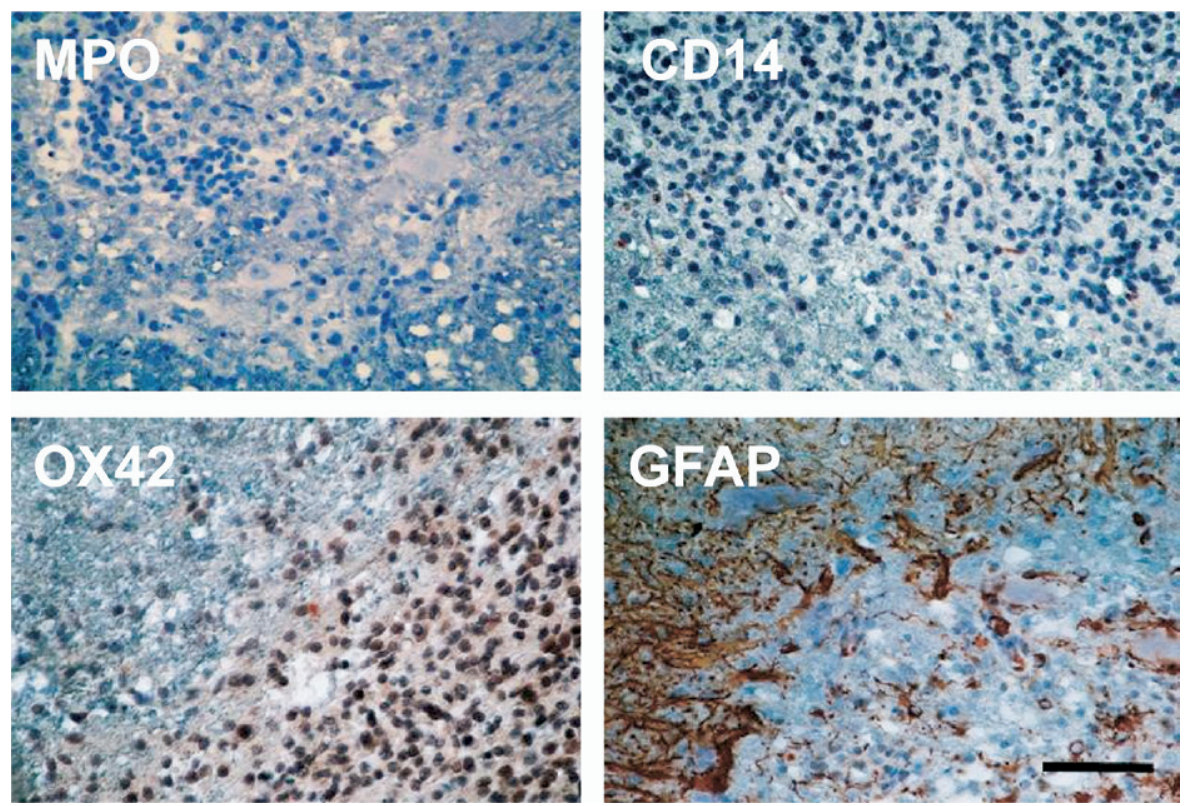

Figure 4. Immunohistochemistry of spinal cord sections from the control group at 3 days using MPO, CD14, OX42, and GFAP antibodies, respectively. The 0X42-stained infiltrating cells in the infarct area and the GFAPstained cells in the surrounding areas indicate that microglial and astroglial activation was a major pathologic feature after injury. Scale bar, $50 \mu \mathrm{m}$. MPO, myeloperoxidase; GFAP, glial fibrillary acidic protein. proach when pharmacologic abolishment of the MEK/ERK pathway is desired.

Despite the accumulating data showing beneficial effects of U0126, the mechanisms underlying its neuroprotection still remain elusive. In the present study, we observed severe cellular infiltration into the infarct area associated with markedly elevated IL- $1 \beta$ production after I/R injury. Immunohistochemical studies showed that the infiltrating cells were not immunostained by the MPO, CD14, or GFAP antibodies, but reactive to the OX42 antibody. Because the OX42 antibody used in our study was directed against

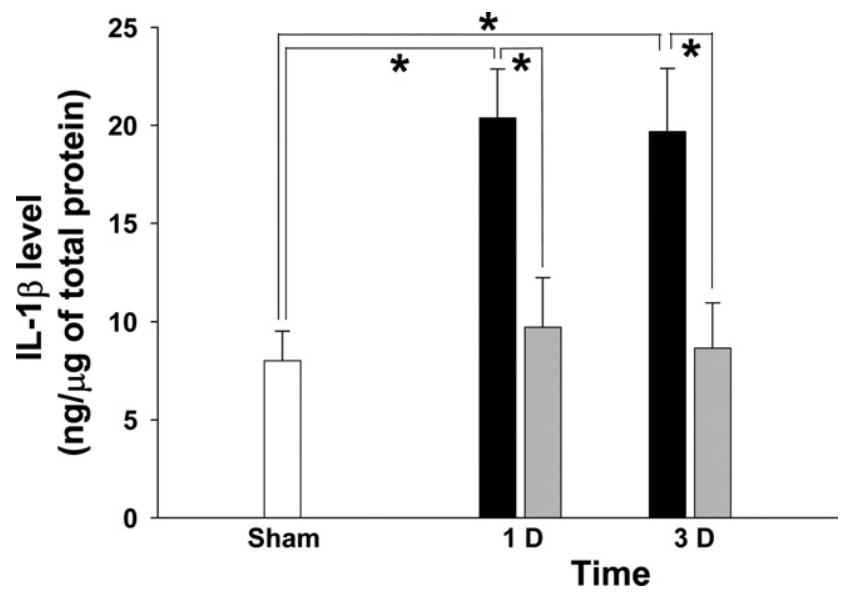

Figure 5. IL-1 $\beta$ content measured by enzyme-linked immunosorbent assay. I/R injury significantly increased IL-1 $\beta$ levels in the controls (black bars). U0126 (gray bars) reduced IL-1 $\beta$ to values comparable to that in the sham group (white bar) $\left({ }^{*} P=.021\right.$ ). IL, Interleukin.
CD11b, an important surface marker of microglia, ${ }^{29}$ the OX42 immunoreactivity indicates that the infiltrating cells were neither neutrophils nor macrophages, but microglia in nature. Microglia are considered the principal immune effector cells of the CNS responding to a variety of pathologic event. ${ }^{30}$ It is believed that neurotoxic molecules and surface markers expressed by activated microglia are detrimental. ${ }^{31-35}$ Previous evidence has also shown that IL- $1 \beta$ is a critical cytokine released by activated microglia in an early period after cerebral ischemia. ${ }^{33}$ These data, together with our findings, strongly support the importance of inflammatory processes in the pathogenesis of CNS I/R injury.

The link between the MEK/ERK pathway and inflammatory cascades is unclear. In different types of cells, blockade of the MEK/ERK pathway with a selective inhibitor PD98059 was shown to inhibit arachidonic acid release. $^{36-38}$ Similarly, U0126 inhibited IL- $1 \beta$-dependent arachidonic acid release in cells. ${ }^{39}$ More recently, it was demonstrated that inhibiting the ERK1/2 pathway with U0126 significantly reduced proinflammatory cytokine IL-1 expression in focal cerebral ischemia. ${ }^{23}$ In the present study, MEK/ERK inhibition with U0126 dramatically reduced microglial accumulation and IL- $1 \beta$ expression, resulting in improved neuronal survival. Taken together, these data suggest a role of the MEK/ERK pathway in the inflammatory responses after CNS ischemia, and that neuroprotection provided by U0126 is at least in part mediated by its inhibitory effects on microglial activation and IL- $1 \beta$ production.

The GFAP-stained cells adjacent to the infarct area demonstrated features of reactive astrocytes, including hypertrophy and process extension, as described previously (Figure 4$).{ }^{40}$ Reactive astrocytes are a prominent feature of 
cellular response to various forms of CNS injury. Although reactive astrocytes were found to provide activities that protect tissue and preserve function after mild or moderate spinal cord injury, ${ }^{41}$ reactive astrogliosis has been generally regarded as a major impediment to axonal regeneration and detrimental to functional outcome. ${ }^{42-44}$ Further studies are warranted to elucidate the roles of reactive astrocytes in spinal cord I/R injury.

\section{Conclusions}

I/R injury of the spinal cord induced ERK1/2 phosphorylation followed by pronounced microglial infiltration and IL-1 $\beta$ production. By inhibiting the MEK/ERK pathway, U0126 significantly attenuated cellular infiltration and cytokine production, resulting in neuronal and functional salvage. The MEK/ERK pathway appears to be an important mediator of inflammatory reactions after $\mathrm{I} / \mathrm{R}$ injury of the spinal cord and may serve as a potential therapeutic target of pharmacologic interventions. ${ }^{35}$

\section{References}

1. Chang L, Karin M. Mammalian MAP kinase signaling cascades. Nature. 2001;410:37-40.

2. Boulton TG, Nye SH, Robbins DJ, Ip NY, Radziejewka E, Morgenbesser SD, et al. ERKs: a family of protein-serine/threonine kinase that are activated and tyrosine phosphorylated in response to insulin and NGF. Cell. 1991;65:663-75.

3. Nishida E, Gotoh Y. The MAP kinase cascade is essential for diverse signal transduction pathways. Trends Biochem Sci. 1993;18:128-31.

4. Xia Z, Dickens M, Raingeaud J, Davis RJ, Greeberg ME. Opposing effects of ERK and JUNK/p38 MAP kinases on apoptosis. Science. 1995;270:1326-31.

5. Segal RA, Greenberg ME. Intracellular signaling pathways activated by neurotrophic factors. Апnи Rev Neurosci. 1995;19:463-89.

6. Stanciu M, Wang Y, Kentor R, Burke N, Watkins S, Kress G, et al. Persistent activation of ERK contributes to glutamate induced oxidative toxicity in a neuronal cell line and primary neuron cultures. J Biol Chem. 2000;275:12200-6.

7. Tang D, Wu D, Hirao A, Lahti JM, Liu L, Mazza B, et al. ERK activation mediates cell cycle arrest and apoptosis after DNA damage independently of p53. J Biol Chem. 2002;277:12710-7.

8. Subramaniam S, Zirrgiebel U, von Bohlen Und Halbach O, Strelau J, Laliberte C, Kaplan DR, et al. ERK activation promotes neuronal degeneration predominantly through plasma membrane damage and independently of caspase-3. J Cell Biol. 2004;165:357-69.

9. Satoh T, Nakatsuka D, Watanabe Y, Nagata I, Kikuchi H, Namura S. Neuroprotection by MAPK/ERK kinase inhibition with U0126 against oxidative stress in a mouse neuronal cell line and rat primary cultured cortical neurons. Neurosci Lett. 2000;288:163-6.

10. Mori T, Wang X, Jung JC, Sumii T, Singhal AB, Fini ME, et al. Mitogen-activated protein kinase inhibition in traumatic brain injury: in vitro and in vivo effects. J Cereb Blood Flow Metab. 2002;22:444-52.

11. Murray B, Alessandrini A, Cole AJ, Yee AG, Furshpan EJ. Inhibition of the p44/42 MAP kinase pathway protects hippocampal neurons in a cell-culture model of seizure activity. Proc Natl Acad Sci U S A. 1998;95:11975-80

12. Alessandrini A, Namura S, Moskowitz MA, Bonventre JV. MEK1 protein kinase inhibition protects against damage resulting from focal cerebral ischemia. Proc Natl Acad Sci U S A. 1999;96:12866-9.

13. Namura S, Iihara K, Takami S, Nagata I, Kikuchi H, Matsushita K, et al. Intravenous administration of MEK inhibitor U0126 affords brain protection against forebrain ischemia and focal cerebral ischemia. Proc Natl Acad Sci U S A. 2001;98:11569-74.
14. Cho DG, Mullory MR, Chang PA, Johnson MD, Aharon AS, Robison TA, et al. Blockade of the extracellular signal-regulated kinase pathway by U0126 attenuates neuronal damage following circulatory arrest. J Thorac Cardiovasc Surg. 2004;127:1033-40.

15. Pearson VL, Rothwell NJ, Toulmond S. Excitotoxic brain damage in the rat induces interleukin-1beta protein in microglia and astrocytes: correlation with the progression of cell death. Glia. 1999;25:311-23.

16. Gibson RM, Rothwell NJ, Le Feurvre RA. CNS injury: the role of the cytokine IL-1. Vet J. 2004;168:230-7.

17. Lucas SM, Rothwell NJ, Gibson RM. The role of inflammation in CNS injury and disease. Br J Pharmacol. 2006;147(Suppl 1):S232-40.

18. Allan SM, Rothwell NJ. Cytokines and acute neurodegeneration. Nat Rev Neurosci. 2001;2:734-44.

19. Boutin H, LeFeuvre RA, Horai R, Asano M, Iwakura Y, Rothwell NJ. Role of IL-1alpha and IL-1beta in ischemic brain damage. J Neurosci. 2001;21:5528-34.

20. Rothwell N. Interleukin-1 and neuronal injury: mechanisms, modification, and therapeutic potential. Brain Behav Immun. 2003;17:152-7.

21. Loddick SA, Wong ML, Bongiorno PB, Gold PW, Licinio J, Rothwell NJ. Endogenous interleukin-1 receptor antagonist is neuroprotective. Biochem Biophys Res Commun. 1997;234:211-5.

22. Lazovic J, Gasu A, Lin HW, Rothstein RP, Krady JK, Smith MB, et al. Neuroinflammation and both cytotoxic and vasogenic edema are reduced in interleukin- 1 type 1 receptor-deficient mice conferring neuroprotection. Stroke. 2005;36:2226-31.

23. Wang ZQ, Wu DC, Huang FP, Yang GY. Inhibition of MEK/ERK 1/2 pathway reduces pro-inflammatory cytokine interleukin-1 expression in focal cerebral ischemia. Brain Res. 2004;996:55-66.

24. Marsala M, Yaksh TL. Transient spinal ischemia in the rat: characterization of behavioral and histopathological consequences as a function of the duration of aortic occlusion. J Cereb Blood Flow Metab. 1994;14:526-35.

25. Lu K, Liang CL, Chen HJ, Chen SD, Hsu HC, Liliang PC, et al. Injury severity and cell death mechanisms: effects of concomitant hypovolemic hypotension on spinal cord ischemia-reperfusion in rats. Exp Neurol. 2004;185:120-32.

26. Duggal N, Lach B. Selective vulnerability of the lumbosacral spinal cord after cardiac arrest and hypotension. Stroke. 2002;33:116-21.

27. Lau D, Mollnau H, Eiserich JP, Freeman BA, Daiber A, Gehling UM, et al. Myeloperoxidase mediates neutrophil activation by association with CD11b/CD18 integrins. Proc Natl Acad Sci U S A. 2005;102: 431-6.

28. Landmann R, Ludwig C, Obrist R, Obrecht JP. Effect of cytokines and lipopolysaccharide on CD14 antigen expression in human monocytes and macrophages. J Cell Biochem. 1991;47:317-29.

29. Roy A, Fung YK, Liu X, Pahan K. Up-regulation of microglial CD11b expression by nitric oxide. J Biol Chem. 2006;281:14971-80.

30. Gonzalez-Scarano F, Baltuch G. Microglia as mediators of inflammatory and degenerative diseases. Annu Rev Neurosci. 1999;22: 219-40.

31. Ling EA, Wong WC. The origin and nature of ramified and amoeboid microglia: a historical review and current concepts. Glia. 1993; 7:9-18

32. Wu DC, Jackson-Lewis V, Vila M, Tieu K, Teismann P, Vadseth C, et al. Blockade of microglial activation is neuroprotective in the 1-methyl-4-phenyl-1,2,3,6-tetrahydropyridine mouse model of Parkinson disease. J Neurosci. 2002;22:1763-71.

33. Barcia C, Sanchez Bahillo A, Fernandez-Villalba E, Bautista V, Poza Y, Poza M, Fernandez-Barreiro A, et al. Evidence of active microglia in substantia nigra pars compacta of parkinsonian monkeys 1 year after MPTP exposure. Glia. 2004;46:402-9.

34. Rock RB, Gekker G, Hu S, Sheng WS, Cheeran M, Lokensgard JR, et al. Role of microglia in central nervous system infections. Clin Microbiol Rev. 2004;17:942-64.

35. Mabuchi T, Kitagawa K, Ohtsuki T, Kuwabara K, Yagita Y, Yanagihara $\mathrm{T}$, et al. Contribution of microglia/macrophages to expansion of infarction and response of oligodendrocytes after focal cerebral ischemia in rats. Stroke. 2000;31:1735-43.

36. Hazan I, Dana R, Granot Y, Levy R. Cytosolic phospholipase A2 and its mode of activation in human neutrophils by opsonized zymosan. Correlation between $42 / 44 \mathrm{kDa}$ mitogen-activated protein kinase, cy- 
tosolic phospholipase $\mathrm{A} 2$ and NADPH oxidase. Biochem $J$. 1997;326:867-76.

37. Wheeler-Jones C, Abu-Ghazaleh R, Cospedal R, Houliston RA, Martin J, Zachary I. Vascular endothelial growth factor stimulates prostacyclin production and activation of cytosolic phospholipase A2 in endothelial cells via $\mathrm{p} 42 / \mathrm{p} 44$ mitogen-activated protein kinase. FEBS Lett. 1997;420:28-32.

38. Zhang C, Baumgartner RA, Yamada K, Beaven MA. Mitogenactivated protein (MAP) kinase regulates production of tumor necrosis factor-alpha and release of arachidonic acid in mast cells. Indications of communication between p38 and p42 MAP kinases. J Biol Chem. 1997;272:13397-402.

39. Newton R, Cambridge I, Hart LA, Stevens DA, Lindsay MA, Barnes PJ. The MAP kinase inhibitors, PD098059, U0126 and SB203580, inhibit IL-1beta-dependent PGE(2) release via mechanistically distinct processes. Br J Pharmacol. 2000;130:1353-61.
40. Eng LF, Ghirnikar RS. GFAP and astrogliosis. Brain Pathol. 1994;4: 229-37.

41. Faulkner JR, Herrmann JE, Woo MJ, Tansey KE, Doan NB, Sofroniew MV. Reactive astrocytes protect tissue and preserve function after spinal cord injury. J Neurosci. 2004;24:2143-55.

42. Rudge JS, Silver J. Inhibition of neuritic growth on astroglial scars in vitro. J Neurosci. 1990;10:3594-603.

43. McKeon RJ, Schreiber RC, Rudge JS, Silver J. Reduction of neuritic outgrowth in a model of glial scarring following CNS injury is correlated with the expression of inhibitory molecules on reactive astrocytes. J Neurosci. 1991;11:3398-411.

44. Menet V, Gimenez y Ribotta M, Chauvet N, Drian MJ, Lannoy J, Collucci-Guyon E, et al. Inactivation of the glial fibrillary acidic protein gene, but not that of vimentin, improves neuronal survival and neuritic growth by modifying adhesion molecule expression. $\mathrm{J} \mathrm{Neu}$ rosci. 2001;21:6147-58.

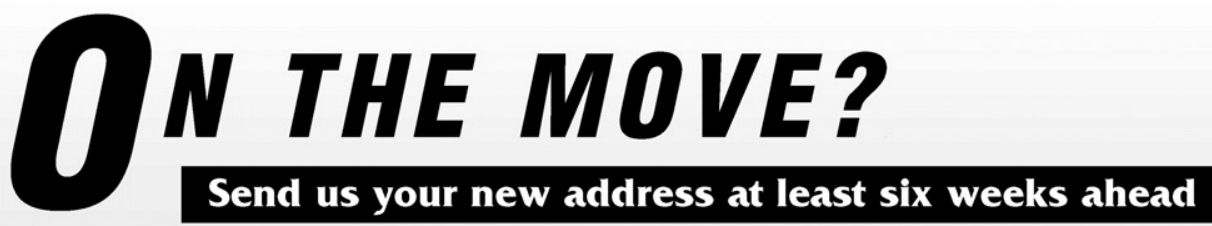

Don't miss a single issue of the journal! To ensure prompt service when you change your address, please photocopy and complete the form below.

Please send your change of address notification at least six weeks before your move to ensure continued service. We regret we cannot guarantee replacement of issues missed due to late notification.

\section{JOURNAL TITLE:}

Fill in the title of the journal here.

\section{OLD ADDRESS:}

Affix the address label from a recent issue of the journal here.

\section{NEW ADDRESS:}

Clearly print your new address here.

Name

Address

City/State/ZIP
COPY AND MAIL THIS FORM TO:

Elsevier Inc.

Subscription Customer Service

6277 Sea Harbor Dr

Orlando, FL 32887
OR FAX TO:

407-363-9661

OR E-mail:

elspcs@elsevier.com
OR PHONE:

800-654-2452

Outside the U.S., call

407-345-4000 